\title{
Management of Eclampsia and Imminent Eclampsia, Maternal and Perinatal Outcome in 666 Cases-2003-2007 at Government Maternity Hospital in Hyderabad
}

\author{
Pratibha Devabhaktuni, Mahita Reddy Addula, Malati Ponnur, Bhavana Kasu, Shobha Ramakoti, \\ Harita Reddy
}

Department of Obstetrics and Gynaecology, Government Maternity Hospital, Osmania Medical College, Hyderabad, India Email:dpdnk@yahoo.com

How to cite this paper: Devabhaktuni, P., Addula, M.R., Ponnur, M., Kasu, B., Ramakoti, S. and Reddy, H. (2017) Management of Eclampsia and Imminent Eclampsia, Maternal and Perinatal Outcome in 666 Cases-2003-2007 at Government Maternity Hospital in Hyderabad. Open Journal of Obstetrics and Gynecology, 7, 193-207. https://doi.org/10.4236/ojog.2017.72021

Received: December 27, 2016

Accepted: February 18, 2017

Published: February 21, 2017

Copyright ( $) 2017$ by authors and Scientific Research Publishing Inc. This work is licensed under the Creative Commons Attribution International License (CC BY 4.0).

http://creativecommons.org/licenses/by/4.0/

\begin{abstract}
Objective: This is an audit to evaluate the maternal and perinatal outcome in eclampsia and imminent eclampsia with the management adopted at a tertiary hospital. Methods: During a period of 34 months, from 2003-2007 at Government maternity hospital, Osmania medical college, Hyderabad, 666 women with eclampsia and imminent eclampsia were managed. The number of eclampsia and imminent eclampsia (IE) was 532 and 134, respectively. We have analyzed the clinical profile, parity, age, degree of proteinuria, the period of gestation in weeks, the antenatal care, the number of antenatal visits, referrals from other hospitals, the diastolic B.P. at the time of admission, the recurrence of convulsions and the complications. 1) All the cases of eclampsia and IE were managed with magnesium sulphate as an anticonvulsant. 2) Oral nifedipine, IV labetalol, sublingual nifedipine and nitroglycerine infusion were used to control severe hypertension. 3) Prostaglandin E1 (PGE1) was used for induction of labour (IOL), $25 \mathrm{mcg} \times 4^{\text {th }}$ hrly, vaginal route and $50 \mathrm{mcg}$ for less than 28 weeks gestation, in 290/424 cases of IOL. Other methods of IOL were employed in 134 cases. Results: Eclampsia $(n=532)$ occurred antepartum in $407(75.56 \%)$, intrapartum in $76(14.28 \%)$, post partum in $46(8.64 \%)$ and intercurrent in $3(0.5 \%)$ patients. The period of gestation was $<28$ weeks in 86 , 28 - 34 weeks in $228,>34$ weeks in 340 patients. Induction of labour with misoprostol was done in 290 with vaginal delivery in 235 (81\%) and lower segment caesarean section (LSCS) for failed IOL in 55 (19\%) and other methods of IOL were used in 134 . The total number of deliveries was 656 , with vaginal deliveries in 336 (66.46\%) patients, ceasarean deliveries in 220 (33.54\%) patients. Ten patients died undelivered. Maternal mortality was $17 / 666-2.55 \%$. Cerebrovascular events were responsible in 13/17 (76.46\%) patients, pulmo-
\end{abstract}


nary embolisim in 2, aspiration pneumonia in one and sepsis in one. The perinatal mortality was $167 / 582$ (28.69\%), PNM when birth weight was $>1.5 \mathrm{~kg}$ was 59/426 (13.84\%), intrauterine fetal deaths at admission were 54 (8.5\%), there were four sets of twins. Conclusions: 1) More effective measures to control hypertension and routine administration of anticonvulsant, magnesium sulphate to women with eclampsia should be practised from the first referral unit itself. 2) Our caesarean delivery rate of $33.54 \%$ in the very high risk cases of eclampsia and imminent eclampsia is very low compared to others. 3) Induction of labour with misoprostol was successful in $81 \%$ with consequent reduction in caesarean section rate and morbidity and mortality associated with caesarean deliveries. Misoprostol has proved to be a safe and effective inducing agent in eclampsia. 4) The maternal mortality in our series is $2.55 \%$.

\section{Keywords}

Eclampsia, Misoprostol, Maternal Mortality, C. Section

\section{Introduction}

In India the causes of maternal deaths are haemorrhage- $25.6 \%$, sepsis -13 percent, preeclampsia and eclampsia-11.9 percent, abortions-8 percent, obstructed labour-6.2 percent and other causes account for 35.3 percent of maternal deaths [1]. According to RGI estimates for the year 2000, maternal mortality rate for India was 407 per 100,000 live births. Eclampsia accounts for 50,000 maternal deaths worldwide annually.

A WHO systematic analysis of global causes of maternal death reports $73 \%$ of all maternal deaths due to direct obstetric causes and $27.5 \%$ due to indirect causes. Haemorrhage accounted for $27.1 \%$, hypertensive disorders $14 \%$, sepsis $10.7 \%$, abortion $7.9 \%$, embolism $3.2 \%$ and other direct causes $9.6 \%$ [2]. The leading causes of death were determined as hypertension $29.4 \%$, haemorrhage $21.56 \%$, sepsis $15.05 \%$, and medical disorders $12 \%$ in an Indian study [3]. A case fatality rate of $4.96 \%$ has been reported in eclampsia from Midnapur Medical College [4]. In the year 2012 the MMR was 167 and it is predicted that India may achieve the goal of MMR < 100 by 2016 [5]. Mortality from eclampsia ranges from approximately $1 \%$ in the developed world, to as high as $15 \%$ in the developing world [6]. From an MMR of 407 in 2000, India may achieve an MMR of 100 by 2017 . Hence reduction of maternal mortality due to eclampsia is the objective of this audit.

Evidence from the Collaborative Eclampsia Trial [7] has shown that women allocated magnesium sulphate had a 52\% lower risk of recurrent convulsions versus those allocated diazepam and a 67\% lower risk of recurrent convulsions than those administered phenytoin. From these results magnesium sulphate has become the first drug of choice to control convulsions in eclampsia. The maternal mortality was non-significantly lower among women $(\mathrm{n}=453)$ allocated magnesium sulphate, $3.8 \%$ compared to diazepam $5.1 \%(n=452)$ and $2.6 \%$ in 
those treated with magnesium sulphate $(n=388)$ compared to $5.2 \%$ treated with phenytoin $(\mathrm{n}=387)$.

The Magpie Trial [8], a randomised placebo controlled trial demonstrated that magnesium sulphate is effective in considerably reducing the risk of eclampsia for women with preeclampsia. The conclusions of the Magpie trial [8] were, 11 per 1000 fewer women allocated magnesium sulphate had an eclamptic convulsion. Women allocated magnesium sulphate had a 58\% lower risk of eclampsia. A reduction in the risk of placental abruption was also noted in those allocated magnesium sulphate.

In women with severe preeclampsia, it was necessary to treat 63 women to prevent one seizure and 109 women had to be treated to prevent one seizure in women with non severe preeclampsia [8].

In our study women with imminent eclampsia were administered magnesium sulphate and delivered. Women with severe preeclampsia, Blood pressure of 160/110 and more, uncontrolled with antihypertensives also are recommended to receive magnesium sulphate and be delivered when interventionist management was decided upon.

Shirish S. Sheth [9] commenting on Magpie trial expressed his opinion that hundreds of thousands of women could benefit from the evidence yielded by the two studies, the Collaborative Eclampsia Trial-1995 and the Magpie Trial-2002. He commented that international organizations like, the International Federation of Gynecology and Obstetrics and the International Confederation of Midwives could help to make sure that frontline clinicians are trained to use the drug magnesium sulphate.

The Hypitat Trial [10] concluded that induction of labour after 36 weeks gestation is associated with improved maternal outcome and should be advised for women with mild hypertensive disease beyond 37 weeks gestation. The Hypitat Trial [10] was undertaken as strong practice variations exist in the Netherlands for treatment of women with gestational hypertension or mild preeclampsia beyond 36 weeks gestation. Labour was induced with amniotomy + oxytocin or intravaginal or intracervical prostaglandins depending on the Bishop score of 6 . The results of the Hypitat Trial [10] that induction of labour was associated with a reduced risk of severe hypertension or HELLP syndrome and subsequent reduced need for caesarean section, emphasize that this could be one preventive measure to reduce the risk of eclampsia between 37 to 40 weeks gestation.

In the UK, substandard care contributes to $72 \%$ of maternal deaths that are related to hypertensive disease in pregnancy and to $96 \%$ of those in the Netherlands [11]. In the Dutch enquiry [11], no instructions about danger signs to women had been documented in $80 \%$ of cases. Therefore patient education is of major importance. Risks of occurrence and recurrence of $10 \%$ for previous mild disease and upto $40 \%$ for severe disease and perinatal mortality and morbidity should be explained to women [12].

Hence even in our country, India, there is a need for introspection and to focus on the development of infrastructure facilities in the health department if 
maternal deaths have to be averted.

\section{Material and Methods}

During a period of 34 months, from 2003-2007 at Government maternity hospital, Osmania Medical College, Hyderabad, 666 women with eclampsia and imminent eclampsia were managed. Eclampsia were 532, imminent eclampsia (IE) were 134. The total number of deliveries per year was 160,00 to 180,00 during 2003 to 2006 and 24000 during the year 2007. This is an audit of management of eclampsia in a tertiary care teaching Institute in Hyderabad.

A detailed history was taken regarding the previous antenatal care, the period of gestation, any medications given prior to referral-antihypertensives, anticonvulsants, the number of convulsions, H/o labour pains, perception of foetal movements, urine output. The general condition of the patient was assessed including the neurological status and an obstetric examination was made to determine the weeks of gestation, fetal viability, uterine contractions and a per vaginal examination was done to see if she was in active labour.

The investigations included CBC with plalelet count, urine for proteinuria, complete urine analysis, clotting time, bleeding time, serum uric acid, serum creatinine, blood sugar, liver function tests, an obstetric ultrasound examination, doppler study of the umbilical and middle cerebral artery in cases of imminent eclampsia and some cases of eclampsia were done in addition to HIV I \& II \& HBsAg. Coagulation profile was done, when considered necessary.

We have analyzed the clinical profile, parity, age, degree of proteinuria, the period of gestation in weeks, the antenatal care, the number of antenatal visits, referrals from other hospitals, the diastolic B. P. at the time of admission, the recurrence of convulsions and the complications.

The methods used for induction of labour (IOL), the vaginal delivery and caesarean rate, the maternal mortality rate and perinatal outcome have been analyzed.

There are certain limitations to this study. Eclampsia being an emergency situation, sometimes the attendants would not bring all the previous medical records.

\section{Methods}

\subsection{Anticonvulsant}

All the cases of eclampsia and imminent eclampsia were managed with magnesium sulphate as an anticonvulsant. We followed the Pritchard's regime of 4 gms I.V and $10 \mathrm{gms} \mathrm{I/M}$ at the time of admission and $5 \mathrm{gms} \mathrm{I} / \mathrm{M}$ fourth hrly after checking urine output, kneejerks and respiratory rate. For recurrent convulsions phenytoin, lorazepam, diazepam or midazolam were used in different cases.

\subsection{Antihypertensives}

Oral nifedipine, IV labetalol, sublingual nifedipine and nitroglycerine infusion were used to control severe hypertension. Before the availability of IV labetalol, 
sublingual nifidepine was used to control severe hypertension to avert cerebro vascular haemorrhage and prevent maternal mortality. Intravenous hydralazine was unavailable and hence was never used.

Oral nifedipine was the drug of choice to control hypertention. Alpha methyl dopa and T. labetalol were the other drugs used.

\subsection{Methods of Labour Induction}

T. PGE1 was used for induction of labour, $25 \mathrm{mcg}$ fourth hourly, by the vaginal route, in 290/424 cases of induction of labour. Prostaglandin E1, 50 mcgs dosage 4th hourly was used for gestational ages 20 to 28 weeks depending on the response.

Other methods of labour induction and augmentation were used in 134 women. Oxytocin for induction and acceleration of labour, ARM-artificial rupture of membranes or amniotomy, intracervical dinoprostone gel placement and extra amniotic instillation of ethacridine lactate for second trimester abortions were the other methods used.

\subsection{Perinatal Mortality and Survival}

$\mathrm{Chi}^{2}$ tests of significance, between frequencies of perinatal deaths, birth weight and caesarean deliveries among eclampsia cases were done.

\section{Results}

\subsection{Antenatal Care}

In our study of 666 cases of eclampsia and imminent eclampsia, $16.27 \%$ were among the booked cases with three or more antenatal visits. As per the history $16 \%$ had no antenatal checkup and $67.73 \%$ had one or two antenatal visits. Referrals from Andhra Pradesh Vaidya Vidhana Parishad hospitals, district and private hospitals constituted $48.75 \%$ of the total.

As $16 \%$ had no antenatal checkup and $67.73 \%$ had only one or two antenatal visits, the time of onset of hypertension could not be ascertained with certainty.

\subsection{Time of Onset of Convulsions}

Eclampsia and IE: Antepartum in 407 (75.56\%), intrapartum in 76 (14.28\%), post partum in $46(8.64 \%)$ and inter current in 3 cases $(0.5 \%)$.

\subsection{Gravida Status}

Among 469 pregnant women with eclampsia and IE, 321 women (68.4\%) wereprimies, 90 women (19.18\%) were gravida 2, 30 women (6.39\%) were gravida 3, and remaining 28 women were gravida 4 and $4+$.

\subsection{Blood Pressure at Admission}

We have analyzed the diastolic blood pressure at the time of admission. Traditionally diastolic hypertension was considered to indicate the severity, specially in the young, since systolic blood pressure is subject to fluctuations in relation to 
external stimuli. Recently systolic hypertension has been considered equally significant.

Diastolic blood pressure at the time of admission was $(\mathrm{n}=547)$ : Diastolic $\mathrm{BP}>110 \mathrm{mmHg}$ in 189 cases (34.55\%), $100-110$ in 240 (44\%) and <100 in 118 (21.55\%) of cases.

\subsection{The Period of Gestation $(n=654)$}

Gestational age was less than 28 weeks in 86 (13.14\%), 28 - 34 weeks in 228 (34.86\%) and more than 34 weeks in 340 (51.98\%) cases.

\subsection{Degree of Proteinuria: $N=339$}

The severity of proteinuria observed in 339 patients was one+ in 95 (28.02\%), two+ in 95 (28.02\%), three+ in 57 (16.81\%), four+ in $32(9.43 \%)$ and nil in 60 $(17.69 \%)$ cases.

\subsection{IOL with PGE1}

Induction of labour with PGE1 (misoprostol) was done in 290, with vaginal delivery in 235 (81\%) and LSCS for failed IOL in 55 (19\%). Other methods of IOL were employed in 134 cases.

\subsection{Mode of Delivery}

Eclampsia-532, IE-134, total of 666 cases: Vaginal deliveries were 435 (66.32\%), and caesarean deliveries were 221 (33.68\%). Ten patients died undelivered.

\subsection{Causes of Maternal Mortality}

Maternal mortality was 17/666-(2.55\%). Cerebrovascular events were responsible in 13/17 (76.46\%), pulmonary embolisim in two, aspiration pneumonia in one and sepsis in one. Primies were 15, second pregnancy in one and third in another. Ten women died undelivered within six to twenty four hours of admission. Fourteen had antepartum eclampsia, two had postpartum eclampsia and one had imminent eclampsia among the mortality cases.

\subsection{Perinatal Mortality (PNM)}

The perinatal mortality was $167 / 582(28.69 \%)$, PNM was 59/426 (13.84\%) when birth weight was more than $1.5 \mathrm{~kg}$, and intrauterine fetal deaths at admission were $54(8.5 \%)$. There were four sets of twin gestation.

\subsection{Abruptio Placenta}

Placental abruption was observed in 23/662 (3.47\%) of cases.

The results of the clinical profile are presented in Figure 1, regarding age, parity, degree of proteinuria, the period of gestation when eclampsia \& IE occurred, type of eclampsia and diastolic B. P. at the time of admission. The mode of delivery in 656 women, method of labour induction in 424 cases and the causes of maternal mortality in seventeen women treated for eclampsia and IE are shown 

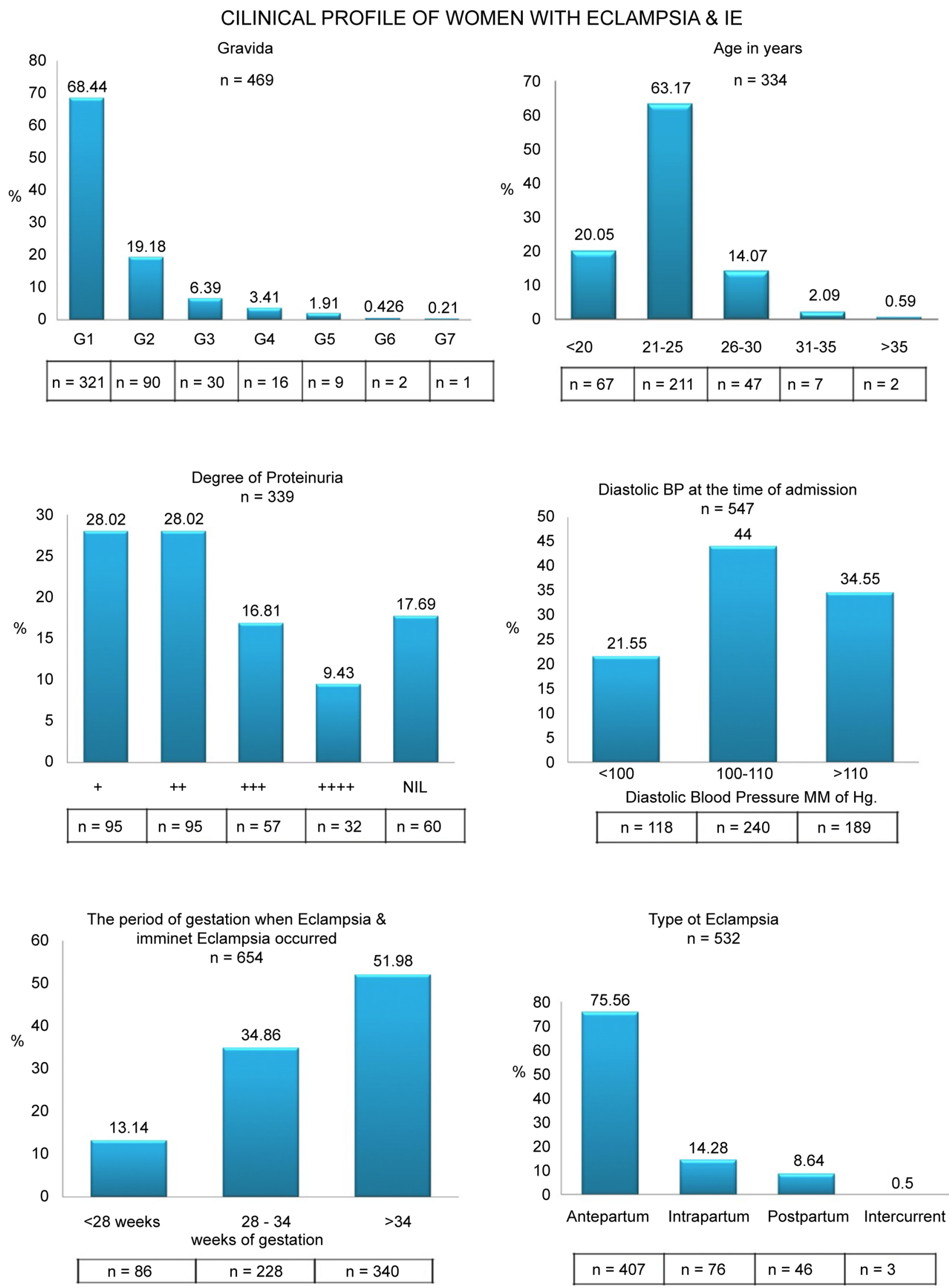

Type ot Eclampsia
$n=532$

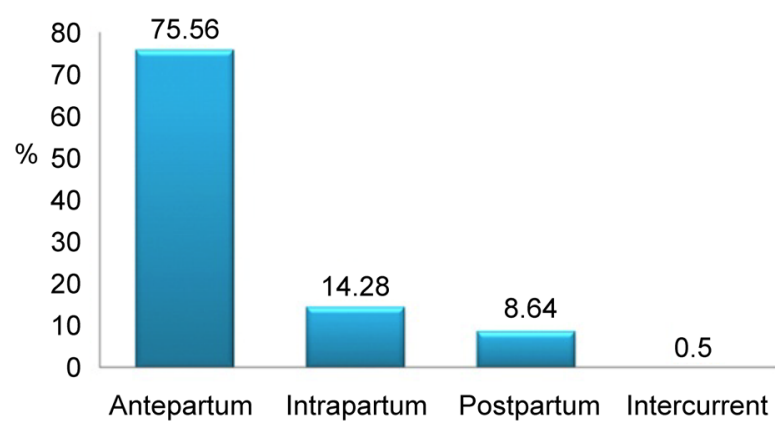

Figure 1. Clinical profile of patients with eclampsia and imminent eclampsia. 
in Tables 1-3. The indications for caesarean delivery are given in Table 4. The perinatal outcome in relation to birth weight and route of delivery and the percentage of perinatal survival and perinatal mortality are outlined in Table 5, Table 6, and Figure 2.

\section{Discussion}

In this study $68.44 \%$ of eclampsia and imminent eclampsia occurred in primies. Thus eclampsia has become a major health problem afflicting primigravidae/ primipara. Though the presence of proteinuria was a necessary diagnostic criteria of preeclampsia as per the working group of NHBPEP - National High Blood Pressure guidelines, education programme-2000, in our study $17.69 \%(60 / 339)$ had no proteinuria when eclampsia occurred and $28.02 \%$ (95/339) had only one plus proteinuria. In our study because of the evidence of end organ dysfunction, a diagnosis of eclampsia or imminent eclampsia was made. These cases without proteinuria were described as atypical cases of preeclampsia and eclampsia by Baha M. Sibai [13]. Society of Obstetrics and Gynaecology of Canada (SOGC)

Table 1. Mode of delivery in eclampsia and imminent eclampsia, $\mathrm{N}=656$.

\begin{tabular}{cccc}
\hline Sl.No. & Mode of delivery & No & $\%$ \\
\hline 1. & Caesarean Deliveries & 221 & 33.68 \\
2. & Vaginal Deliveries & 435 & 66.32 \\
3. & Maternal Mortality $-\mathrm{N}=666$ & 17 & 2.55 \\
4. & Died undelivered & $10 / 17$ & \\
\hline
\end{tabular}

Table 2. Causes of maternal deaths in 17 cases.

\begin{tabular}{cccc}
\hline Sl.no & Causes of Maternal Mortality & No & $\%$ \\
\hline 1. & Cerebro vascular event-C.V.A & 13 & 76.47 \\
2. & Pulmonary embolism & 2 & 11.76 \\
3. & Sepsis & 1 & 5.88 \\
4. & Aspiration pneumonia & 1 & 5.88 \\
5. & TOTAL & 17 & 2.55 \\
\hline
\end{tabular}

Table 3. Methods of induction of labour in 424 cases.

\begin{tabular}{cccc}
\hline Method of labour & Induction & No. & $\%$ \\
\hline Misoprostol-PGE1 & & 290 & 68.39 \\
Vaginal deliveries & PGE1 & 235 & 81 \\
Failed IOL-LSCS & PGE1 & 55 & 19 \\
PGE2 gel & & 11 & 2.59 \\
Oxytocin drip & & 82 & 19.33 \\
Extra amniotic instillation & & 25 & 5.89 \\
Amniotomy alone & & 16 & 3.77 \\
\hline
\end{tabular}

Vaginal delivery-366 $=86.32 \%$, Caesarean delivery-58 $=13.67 \%$. 
Table 4. Indications for LSCS in eclampsia and imminent eclampsia, $\mathrm{N}=220$.

\begin{tabular}{|c|c|}
\hline Indication & No. \\
\hline Failed IOL & 58 \\
\hline Eclampsia, Term gestation & 33 \\
\hline Foetal distress & 26 \\
\hline CPD & 24 \\
\hline One Previous LSCS & 20 \\
\hline Severe Oligoamnios & 14 \\
\hline Previous $\mathrm{BOH}$ & 10 \\
\hline Thick MSL & 6 \\
\hline Placental Abruption & 4 \\
\hline Unfavourable Cervix & 4 \\
\hline Abnormal Doppler & 2 \\
\hline Failure to Progress & 2 \\
\hline PROM & 2 \\
\hline Obstructed Labour & 2 \\
\hline Secondary Arrest of Labour & 2 \\
\hline Breech & 5 \\
\hline Face & 1 \\
\hline Post Dates & 1 \\
\hline Twins & 1 \\
\hline IP Sepsis & 1 \\
\hline Big baby & 1 \\
\hline Pregnancy High risk & 1 \\
\hline
\end{tabular}

Note: In high risk cases of eclampsia, though we mentioned one reason for Caesarean section, many other factors would be taken into consideration: the total number of convulsions, level of consciousness, time from the onset of convulsions, response to induction methods, the salvageability of the foetus, the lab, parameters and the concern of the family.

Table 5. Eclampsia \& imminent eclampsia $(n=666$, 2003-2007). Perinatal outcome in relation to birth weight, $\mathrm{N}=593$.

\begin{tabular}{ccccccc}
\hline WT. & \multicolumn{3}{c}{ LSCS } & & \multicolumn{3}{c}{ VAGINAL } \\
\hline kgs. & Alive & PNM & Total & Alive & PNM & Total \\
\hline$<1.0$ & - & - & - & 3 & 43 & 46 \\
$1.0-1.5$ & 9 & 6 & 15 & 36 & 70 & 106 \\
$1.6-2.0$ & 66 & 7 & 73 & 67 & 24 & 91 \\
$2.1-2.5$ & 67 & 7 & 74 & 76 & 11 & 87 \\
$2.6 \&>$ & 57 & 1 & 58 & 34 & 9 & 43 \\
Total & 199 & 21 & 220 & 216 & 157 & 373 \\
\hline
\end{tabular}

Total no. of babies-593, LSCS-220, Vaginal-373. 
Table 6. Relationship between percentage of perinatal mortality to birth weight \& percentage of C. Section to birth weight.

\begin{tabular}{ccccccccc}
\hline Weight in Kgs & PNM & PNS & Total & \% of PNM & CS & VAG.DE & Total & \% of CS \\
\hline Less than 1.0 & 43 & 3 & 46 & $\mathbf{9 3 . 4 8}$ & 0 & 46 & 46 & 0.00 \\
$1.1-1.5$ & 76 & 45 & 121 & $\mathbf{6 2 . 8 1}$ & 15 & 106 & $\mathbf{1 2 1}$ & 12.40 \\
$1.6-2.0$ & 31 & 133 & 164 & $\mathbf{1 8 . 9 0}$ & 73 & 91 & $\mathbf{1 6 4}$ & 44.51 \\
$2.1-2.5$ & 18 & 143 & 161 & $\mathbf{1 1 . 1 8}$ & 74 & 87 & $\mathbf{1 6 1}$ & 45.96 \\
2.6 \& above & 10 & 91 & 101 & $\mathbf{9 . 9 0}$ & 58 & 43 & $\mathbf{1 0 1}$ & 57.43 \\
Totals & $\mathbf{1 7 8}$ & $\mathbf{4 1 5}$ & $\mathbf{5 9 3}$ & & $\mathbf{2 2 0}$ & $\mathbf{3 7 3}$ & $\mathbf{5 9 3}$ & \\
\hline
\end{tabular}

PNM: Perinatal mortality, PNS: Perinatal survival, CS: Caesarean section, VAG.DE: Vaginal delivery; Perinatal mortality inversely related to birth weight $\mathrm{p}<0.001$; Caesarean delivery $\mathrm{p}<0.001$.

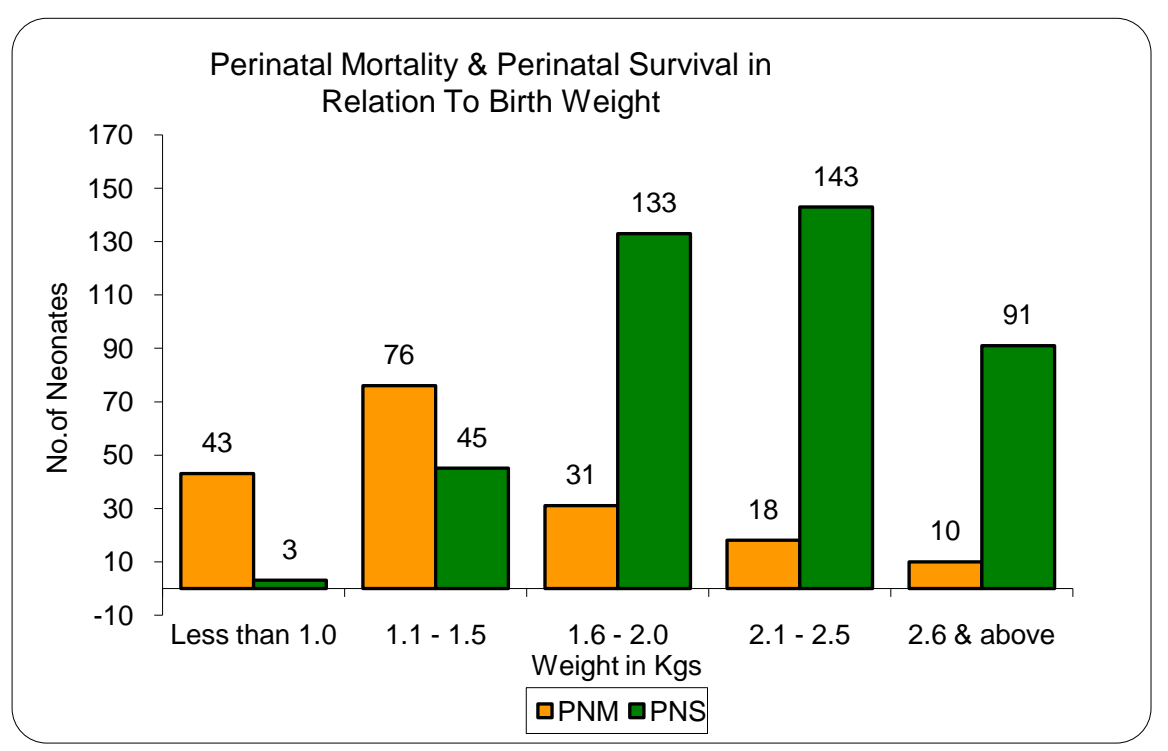

Figure 2. Chart to show increasing perinatal survival with increasing birth weights especially in the more than $1.5 \mathrm{kgs}$ group.

[14] has not included proteinuria as a criteria for the diagnosis of preeclampsia and eclampsia. The ACOG task force on hypertension in pregnancy has stated, in recognition of the syndromic nature of preeclampsia, the task force has eliminated the dependence for diagnosis on the detection of proteinuria.

In our study $13.14 \%$ of eclampsia and imminent eclampsia have occurred at less than 28 weeks gestation, and $34.86 \%$ between 28 to 34 weeks gestation. The perinatal mortality was more when eclampsia occurred at less than 28 weeks and the birth weight was less than $1.5 \mathrm{kgs}$.

In our series of eclampsia- 532 cases, post partum eclampsia (PPE) was noted in $8.64 \%, \mathrm{n}=46$, Antepartum in $75.56 \%, \mathrm{n}=407$, intrapartum in $14.28 \%, \mathrm{n}=76$ and intercurrent eclampsia in $3-0.5 \%$. Matter F. [15] reported PPE in $28 \% \mathrm{n}=$ 110 , antepartum in $53 \% \mathrm{n}=212$ and intrapartum eclampsia in $19 \% \mathrm{n}=77$. The onset of eclamptic convulsions can be antepartum 38\% - 53\%, intrapartum $18 \%$ - 36\%, or postpartum-11\% - 44\% [16].

Almost all cases $91 \%$ of eclampsia develop at or beyond 28 weeks. The re- 
maining cases occur between 21 and 27 weeks of gestation, $7.5 \%$ or at 20 weeks of gestation or earlier 1.5\% [16]. The period of gestation when eclampsia occurs would be significant because it would have a direct bearing on the perinatal outcome. If a number of eclampsia cases occur at early weeks of gestation and at low fetal weights, the perinatal survival would be affected.

In our study $65.55 \%(\mathrm{~N}=358 / 547)$ of women the diastolic blood pressure was less than $110 \mathrm{~mm}$ of mercury and $51.98 \%(\mathrm{~N}=340 / 654)$ of cases of eclampsia and imminent eclampsia occurred after 34 weeks of gestation. From these observations it is evident that even in cases when BP is not in the range of severe preeclampsia, the risk of eclampsia exists.

Placental abruption was noted in $3.47 \%$ of cases in our study. Abruptio placentae $10 \%[15]$ and $7 \%-10 \%[16]$ reported by others.

In our cases even when the pregnant women had three and more antenatal examinations, eclampsia did occur in $16.27 \%$. Another significant point to note is that $48.75 \%$ were referrals from APVVP (Andhra Pradesh Vaidya Vidhana Parishad) hospitals, district hospitals and private hospitals. This indicates that these hospitals were unwilling to take the responsibility of managing the high risk cases of eclampsia. Strengthening the facilities at these hospitals needs to be done to lessen the burden at tertiary hospitals and to save time.

Induction of labour with PGE1 in 290 cases resulted in vaginal delivery rate of $81 \%(n=235)$ and LSCS for failed IOL in PGE1 induced cases was $19 \%(n=55)$. Other methods of labour induction were intracervical placement of PGE 2 gel and extraamniotic instillation of ethacridine lactate in less than 28 weeks gestation for inducing second trimester abortion. Labour augmentation was done with oxytocin drip $n=82 / 424(19.33 \%)$ and artificial rupture of membranes, or amniotomy in [16] (3.77\%).

Vaginal delivery in $436(66.46 \%)$ cases was possible because of successful labour induction with PGE1, placed intravaginally. We conclude from this study that PGE1, for labour induction is safe and effective in high risk cases of eclampsia and imminent eclampsia. It helps to reduce the caesarean rate in high risk cases of eclampsia with attendant morbidity and mortality. Induction of labour was successful in 59\% of 247 women [17]. PGE1, misoprostol and PGE2, dinoprostone gel, both produce a shorter induction delivery interval when compared to oxytocin [17]. Twenty five micrograms of misoprostol for cervical ripening and labor induction every 3 - $6 \mathrm{hrs}$ has been recommended by ACOG 2009 [18]. Vaginal prostaglandins will increase the chance of successful vaginal deliveryRCOG 2006 [19] in severe preeclampsia/eclampsia. The efficacy and safety of vaginal misoprostol for induction of labour with an unfavourable cervix has been reported [20] [21] [22].

Intracervical dinoprostone was used for IOL [23] in cases of severe preeclampsia. Previable foetuses can be delivered with misoprostol induction. Before 28 weeks of gestation, vaginal misoprostol appears to be the most efficient method of labour induction regardless of Bishop score [18].

In the Hypitat Trial [10] for induction of labour, if the Bishop score was 6 or 
lower, cervical ripening was stimulated with intracervical or intravaginal prostaglandins or a balloon catheter. The caesarean section rate of $19 \%$ for failed IOL with misoprostol PGE1 $(\mathrm{n}=290)$ in our study of E \& IE compares with $14 \%$ LSCS for failed induction in hypitat trial [10] for mild PE cases $(n=377)$. Our caesarean delivery rate of $33.54 \%$ in the very high risk cases of eclampsia and imminent eclampsia is very low compared to others. C. Section rate in Magpie trial [8] was $50 \%$ and $48 \%$, in those allocated to magnesium sulphate and placebo respectively in cases of preeclampsia.

Two prospective randomised double blind trials of Javier E. Fonseca [24] and Leila Katz [25] have concluded that their studies do not support the use of high dose corticosteroids in HELLP syndrome complicating E \& PE. Cochrane database systematic review by Matchaba et al. 2009 [26] concluded that there is insufficient data to support high dose corticosteroids for HELLP syndrome. We have not used high dose steroids in any of our cases.

The maternal mortality of $2.55 \%$ in the present study of 666 cases of eclampsia and imminent eclampsia was less than that reported in collaborative eclampsia trial 3.8\% and 2.6\% [7]. Cerebral complications have been reported as the leading cause of maternal deaths in our study $13 / 17-76.47 \%$ which compares with $12 / 18-66 \%$ reported in UK [14]. Acute cerebral complications like intracranial hemorrhage, massive cerebral edema account for more than $75 \%$ of maternal deaths secondary to preeclampsia [14]. A case fatality rate of $22.3 \%$ [27] from Nigeria has been reported. Eclampsia is associated with a maternal mortality rate of $0 \%-1.8 \%$ in developed countries and $14 \%$ in the developing countries [16].

The reported perinatal death rate ranged from $5.6 \%$ to $11.8 \%$ [16]. This high perinatal mortality rate is related to prematurity, placental abruption, severe fetal growth restriction in addition to late referral.

Intrauterine fetal demise at admission, prematurity, placental abruption and severe IUGR by the time eclampsia occurred would all lead to increased perinatal loss [28]. Severe IUGR reported in 24\% (58) and nonsevere IUGR in 76\% (181) in severe preeclampsia (239) during expectant management [28].

In our study IUFD at admission were $54=8.5 \%$. The perinatal mortality was $28.69 \%$ (167/582).This high perinatal mortality could be due to the high number of $\mathrm{E}$ and IE occurring prior to 28 weeks of gestation in $86=13.14 \%$ and another $228=34.86 \%$ occurring between $28-34$ weeks, in addition to abruption in $3.47 \%$ in our series, severe IUGR already existing, pyrexia in a few cases, thick meconium stained liquor in some and late referral, were all the causative factors.

When the estimated foetal weight was less than $1.5 \mathrm{kgs}$, vaginal delivery was the route chosen as the perinatal survival was doubtful, and the lack of consent for abdominal delivery from the family. Excluding the very low birth weight babies less than $1.5 \mathrm{kgs}$, the perinatal mortality in our study was 59/426 $=13.84$ percent.

\section{Conclusions}

1) Our caesarean delivery rate of $33.54 \%$ in the very high risk cases of eclamp- 
sia and imminent eclampsia is very low compared to others.

2) Induction of labour with misoprostol was successful in $81 \%$ with consequent reduction in C. Section rate and morbidity and mortality associated with caesarean deliveries. Misoprostol has proved to be a safe and effective inducing agent in eclampsia.

3) The maternal mortality in our series is $2.55 \%$.

4) More effective measures to control hypertension and routine administration of anticonvulsant, magnesium sulphate to women with eclampsia should be practised from the first referral unit itself.

5) India is emerging as an economic force to reckon with, at this juncture, there is a greater need to strengthen the infrastructure facilities if we have to improve our health indices.

\section{References}

[1] Arora, S.V.P. (2005) Maternal Mortality-Indian Scenario. MJAFI, 61, 214-215.

[2] Say, L. (2014) Global Causes of Maternal Death: A WHO Systematic Analysis. Lancet Glob Health, 2, e323-e333. http://WWW.thelancet.com/lancetgh

[3] Hiralal, K. and Baron, C.A. (2013) Maternal Mortality: A FOGSI Study. The Journal of Obstetrics and Gynaecology of India, 63, 88-95.

[4] Sarkar, M., Basak, S., Mondal, S.K., Das, S., ROY, D., Mandal, J., Mondal, S.C. and Das, S.K. (2013) Maternal Mortality Associated with Eclampsia in an Indian Medical College: A Four Year Retrospective Study. Journal of Medical Science, 4, 394398.

[5] Doke, P.P. (2016) Decline and Disparity in Maternal Mortality in Pre- and PostNational Health Mission Period in India. Indian Journal of Public Health, 60, 294 297. https://doi.org/10.4103/0019-557X.195857

[6] Ghulmiyyah, L. and Sibai, B.M. (2012) Maternal Mortality from Preeclampsia/ Eclampsia. Seminars in Perinatology, 36, 56-59.

https://doi.org/10.1053/j.semperi.2011.09.011

[7] Duey, L. (1995) Which Anticonvulsant for Women with Eclampsia? Evidence from the Collaborative Eclampsia Trial. The Lancet, 345, 1455-1463. https://doi.org/10.1016/S0140-6736(95)91034-4

[8] Duley, L., Farrell, B., Spark, P., Roberts, B., et al.; The Magpie Trial Collaborative Group (2002) Do Women with Pre-Eclampsia, and Their Babies Benefit from Magnesium Sulphate? The Magpie Trial: A Randomised Placebo Controlled Trial. The Lancet, 359, 1877-1890. https://doi.org/10.1016/S0140-6736(02)08778-0

[9] Sheth, S.S. and Chalmers, I. (2002) Magnesium for Preventing and Treating Eclampsia: Time for International Action. The Lancet, 359, 1872-1873. https://doi.org/10.1016/S0140-6736(02)08783-4

[10] Koopmans, C.M., Bijlenga, D., Groen, H., Vigen, S.M.C. and Aarnoudse, J.G. (2009) Induction of Labour versus Expectant Monitoring for Gestational Hypertension or Mild Pre-Eclampsia after 36 Weeks' Gestation (HYPITAT): A Multicentre, OpenLabel Randomized Controlled Trial. Vol. 374, No. 9694, 4, 979-988. www.thelancet.com

[11] Schutte, J.M., Schuitemaker, N.W., van Roosmalen, J. and Steegers, E.A. (2008) Dutch Maternal Mortality C. Substandard Care in Maternal Mortality Due to Hypertensive Disease in Pregnancy in the Netherlands. BJOG, 115, 732-736. 
https://doi.org/10.1111/j.1471-0528.2008.01702.x

[12] Steegers, E.A.P., von Dadelszen, P., Duvekot, J.J. and Pijnenborg, R. (2010) PreEclampsia. The Lancet, 376, 631-644.

[13] Sibai, B.M. and Stella, C.L. (2009) Diagnosis and Management of Atypical Preeclampsia-Eclampsia. American Journal of Obstetrics \& Gynecology, 200, 481.e1481.e7. https://doi.org/10.1016/j.ajog.2008.07.048

[14] Bourjeily and Miller (2009) Obstetric Disorders in the ICU. Clinics In Chest Medicine, 30, 89-102. https://doi.org/10.1016/j.ccm.2008.10.004

[15] Mattar, F. and Sibai, B.M. (2000) Eclampsia VIII: Risk Factors for Maternal Morbidity. American Journal of Obstetrics \& Gynecology, 182, 307-312. https://doi.org/10.1016/S0002-9378(00)70216-X

[16] Sibai, B.M. (2005) Diagnosis, Prevention, and Management of Eclampsia. Obstetrics \& Gynecology, 105, 402-410. https://doi.org/10.1097/01.AOG.0000152351.13671.99

[17] Rose, C.H., Thigpen, B., Bofill, J.A., Cushman, J., May, W.L. and Martin, J.N.J. (2004) Obstetric Implications of Antepartum Corticosteroid Therapy for HELLP Syndrome. Obstetrics \& Gynecology, 104, 1011-1014.

[18] American College of Obstetricians and Gynecologists (ACOG) (2009) Induction of Labour. ACOG Practice Bulletin, No. 107, Washington DC, 12 p.

[19] Royal College of Obstetricians and Gynaecologists (2006) Guideline No. 10(A). Royal College of Obstetricians and Gynaecologists, London, 1-11.

[20] Abbasi, N., Danish, N., Shakoor, F., Praveen, Z. and Bilal, S.A. (2008) Effectiveness and Safety of Vaginal Misoprostol for Induction of Labour in Unfavourable Cervix in 3rd Trimester. Journal of Ayub Medical College Abbottabad, 20, 33-35.

[21] Calder, A., Loughney, A., Weir, C. and Barber, J. (2008) Induction of Labour in Nulliparous and Multiparous Women: A UK, Multicenter, Open-Label Study of Intravaginal Misoprostol in Comparision with Dinoprostone. BJOG, 115, 12791288. https://doi.org/10.1111/j.1471-0528.2008.01829.x

[22] Ferdous, J., Khanam, N.N., Begum, M. and Akhter, S. (2009) Cervical Ripening: Comparative Study between Intracervical Balooning by Foleys Catheter and Intravaginal Misoprostol Tablet. Journal of Bangladesh College of Physicians and Surgeons, 27, 5-12.

[23] Oettle, C., Hall, D., Roux, A. and Grove, D. (2005) Early Onset Severe Pre-Eclampsia: Expectant Management at a Secondary Hospital in Close Association with a Tertiary Institution. BJOG: An International Journal of Obstetrics and Gynaecology, 112, 84-88. https://doi.org/10.1111/j.1471-0528.2004.00262.x

[24] Fonseca, J.E., Mendez, F., Catano, C. and Arias, F. (2005) Dexamethasone Treatment Does Not Improve the Outcome of Women with HELLP Syndrome: A Double-Blind, Placebo-Controlled, Randomized Clinical Trial. American Journal of Obstetrics and Gynecology, 193, 1591-1598. https://doi.org/10.1016/j.ajog.2005.07.037

[25] Katz, L., de Amorim, M.M.R., Figueiroa, J.N., et al. (2008) Postpartum Dexamethasone for Women with Hemolysis, Elevated Liver Enzymes, and Low Platelets (HELLP) Syndrome: A Double-Blind, Placebo-Controlled, Randomized Clinical Trial. American Journal of Obstetrics \& Gynecology, 198, 283.e1-283.e8.

[26] Matchaba, P.T. and Moodley, J. (2009) Withdrawn: Corticosteroids for Hellp Syndrome in Pregnancy. The Cochrane Database of Systematic Reviews, 8, CD002076.

[27] Kullima, A.A., Kawuwa, M.B., Audu, B.M., Usman, H. and Geidam, A.D. (2009) A 5-Year Review of Maternal Mortality Associated with Eclampsia in a Tertiary Institution in Northern Nigeria. Annals of African Medicine, 8, 81-84. 
https://doi.org/10.4103/1596-3519.56233

[28] Haddad, B., Deis, S., Goffinet, F., Daniel, B.J., Cabrol, D. and Sibai, B.M. (2004) Maternal and Perinatal Outcomes during Expectant Management of 239 Severe Preeclampsia Women between 24 and 33 Weeks' Gestation. American Journal of Obstetrics \& Gynecology, 190, 1590-1595. https://doi.org/10.1016/j.ajog.2004.03.050

Submit or recommend next manuscript to SCIRP and we will provide best service for you:

Accepting pre-submission inquiries through Email, Facebook, LinkedIn, Twitter, etc. A wide selection of journals (inclusive of 9 subjects, more than 200 journals)

Providing 24-hour high-quality service

User-friendly online submission system

Fair and swift peer-review system

Efficient typesetting and proofreading procedure

Display of the result of downloads and visits, as well as the number of cited articles Maximum dissemination of your research work

Submit your manuscript at: http://papersubmission.scirp.org/

Or contact ojog@scirp.org 